\title{
Editorial
}

\section{Public health: where should we be in 10 years?}

The change in government and the appointment of a minster of public health should provide the stimulus to refurbish and reinforce public health activities in the United Kingdom. But it is crucial that we seize the opportunity to achieve an effective and realistic outcome. This editorial is written before we have seen the green paper(s) on public health, but shortly after the publication of "The new NHS". Hopefully it will appear before things are set in concrete.

We have recently published a monograph, "Public health, the vision and the challenge", ${ }^{1}$ which was the cornerstone of the Nuffield Trust Rock Carling Lecture in October 1997. This reviewed the major events and concerns of the specialty in the UK in the past 100 years or so. There have been dramatic improvements in health during this time period-but many of the problems of the past still bedevil us today-sometimes in a less serious way or in a slightly different form. They are ignored at our peril. And new public health problems have also emerged.

It is not our intention, or possible, to describe our findings in any detail. We will try, however, to consider how, in the immediate future, we can focus our work so that we do not continue with another cycle of hope and despair.

The major issues influencing health that have been present throughout, have been poverty, housing, nutrition, and the environment. Dramatic falls have occurred in disease incidence, for example, infectious disease, respiratory disease, infant mortality - but new diseases, such as AIDS have appeared. But not all changes have been for the better, and there has been little if any change in some-for example, mental illness and violence. Throughout this time, organisational issues and relationships with groups such as general practitioners, social workers, sanitary engineers, and politicians has been a constant source of concern and often friction. Education, recruitment, both quantity and quality, and insufficient research capability or concern has been a refrain throughout.

We do have a clear and acceptable definition of public health: "Public health is the science and art of preventing disease, prolonging life and promoting health through the organised efforts of society".

It is vital that this definition becomes our focus. To do this our major functions must be: (1) The improvement of the surveillance of the health of the population centrally and locally; (2) The encouragement of policies that promote, maintain, and improve health; (3) Ensuring that the means are available for the evaluation of existing health services.

Thus the public health service must be able to identify and respond to major public health problems, and promote strategies to combat them. If no well tried solution is available the service must ensure that an investigation is undertaken to develop the body of knowledge that will solve the problem and thus identify the means whereby it can be prevented in the future.

In the past 70 years or so, on more than one occasion, public health doctors, as a professional group have become identified with, and been responsible for, the management of individual clinicians (for example, in local authority hospitals in the 1930s), competition in the supply of preventive clinical services with general practitioners, or responsibility for contracting clinical services. This has undoubtedly led to a dilution of concern with those factors that have a major influence on levels of health, increased friction between professional groups, and possibly even been responsible for a delay in the introduction of diphtheria immunisation and thus unnecessary mortality.

If our analysis of the problems and success of public health is accepted, then public health has the following responsibilities and requirements: (1) The ability to handle outbreaks of disease-this implies updating of the law to clarify responsibilities, the development and maintenance of epidemiological skills, and fostering and improving links between public health and microbiological and toxicological laboratories; (2) A major role in the design and implementation of appropriate, accurate information systems related to demographic, social and environmental data and health utilisation and outcome, linked to people and not only events; (3)The involvement in appropriate studies, whether epidemiological, sociological, psychological or statistical, which enable hypotheses to be tested and solutions implemented for the control of ill health. This must be a multi-disciplinary activity; (4) The necessary means and freedom both to identify and to disseminate knowledge of the factors that lead to ill health and possible means of solution. Public health must regain an independent voice and use it; (5) As many of the factors that cause ill health are under the control of other local authority departments or central government the opportunity for public health, as part of a health authority, to intervene may be limited. Some important public health messages are uncomfortable and unpopular politically, and others may have unwelcome resource implications. A way round this must be found.

To fulfil their role effectively, public health practitioners thus have to do certain things: (1) They have to be forthright in the advocacy of programmes that improve health and to state clearly and openly the dangers and consequences of some actions-clinical, environmental or political; (2) They have to be able to influence the budget for public health activities in order that the longer term issues are not omitted in favour of the clamant short-term demands. This is crucial as public health resource needs are always in competition with the needs of clinical services. The latter nearly always take precedencetreatment of individual patients seems far more immediate a priority than changes in health status for the future; (3) They have to have a clear role in helping to guide the policies not only of health authorities, but also of schools, welfare agencies, housing departments, environmental agencies, etc, and practising clinicians in hospital and general practice.

We considered three possible models for the future structure of public health - the return of the medical officer of health; an independent national commission of public health; modification of the present structure.

We do not believe that the first option is desirable for two main reasons - the public health function, as we have stated, is dependent on timely, accurate information, particularly from health service sources. It is unlikely that 
the health authorities would delegate responsibility for this essential function to a local authority employee or alternatively, permit complete freedom of access. Although public health is a multi-disciplinary activity, the role of medically qualified persons is important both in terms of knowledge base for providing guidance as well their role in the surveillance, prevention, and control of disease and the ability to communicate appropriately (and authoritatively) with the public, policy makers, and other practitioners. If public health were not considered to be a mainstream, important health activity, its status particularly in its attraction of able medical graduates, would again diminish.

An independent National Commission of Public Health, with attachments at the local level, is theoretically an attractive option. We considered an appropriate structure, etc, but concluded that it was unlikely to be acceptable, as it would need to both investigate and act, it might stifle local initiative. Also, most importantly, it is unlikely that any government would be bold enough to give the wide remit essential for such a body. A precedent in New Zealand has shown this when uncomfortable decisions have to be made.

We thus felt that reinforcement and modification of the present structure were more realistic. This would mean re-introduction of protected employment conditions for directors of public health. They would be responsible for, and have access to, all information services. Consultant grade public health practitioners employed in each district or board, would function as coordinators, with the duty to guide with advice, not to direct, except in special circumstances. The guidance would be to health authorities/ boards, to bodies concerned with the environment, nutrition, housing, employment, etc, as well as to individual clinicians (hospital and GP). The local public health practitioners would need direct and easy access to expert regional and national institutes, including microbiological and toxicological laboratories. Apart from the expertise provided by academic units, they would thus have access to practical resources with service responsibilities. This suggested change means expansion of the responsibilities of public health practitioners, which could only be achieved by a concomitant increase in numbers and thus capacity.

All the above options imply strengthening public health, giving it a clearer focus, and enabling it to provide independent advice, guidance, and strategic direction. The precise model, and its form, will need wide discussion including consideration of the problems of local governance, relations between and within different authorities including the needs for a regional capacity.

An essential ingredient is the clarification of the role of people required to perform the public health function, their training, staffing, and, of course, the essential recognition of its inter-disciplinary nature. The relations and roles of academic departments, regional and national institutes with service departments need to be clarified.

But it needs to be recognised that public health to fulfil its role means involvement with a local community on two levels. Firstly, the practitioners must work with the people, or their representatives in their community to find the best structure for what requires to be a reciprocal process of communication and a real partnership. Secondly, they must work with and guide those responsible for the planning and provision of those structures and activities that affect health.

The health status of our population has improved considerably in the past 150 years. The work of public health practitioners has contributed to this. We now stand at a crossroads where we can either continue to muddle along or seek to regain our former independent voice and status. There are in addition, three crucial recommendations. Firstly, that many current problems have occurred in one form or another in the past, and solutions were found. Many of our current activities merely "re-invent the wheel". Secondly, to make the "New NHS" work we will need both to work with general practitioners more actively and educate them in epidemiological principles. Thirdly, we must improve our research capability and quality and foster far more the service-academic relation.

We perceive public health as the central medical specialty of the future and hope that it finds the unity and courage to face the challenge of realistic change in pressing for the return of its own independent voice.

W W HOLLAND S STEWART

LSE Health, London School of Economics and Political Science,

Houghton Street, London WC2A $2 A E$

1 Holland W W, Stewart S. Public health, the vision and the challenge. London: Nuffield Trust, 1998. 